\title{
Constitutive Modelling of High Temperature Flow Behaviour for a Low Carbon High Silicon Bainitic Steel
}

\author{
Thiago Marques Ivanisk $a^{* *}$ (D), Tomaz, Fantin de Souza ${ }^{b}$ (D), Jérémy Épp ${ }^{c, d}$ (D), Alexandre da Silva Rocha ${ }^{a}$ (i) \\ ${ }^{a}$ Universidade Federal do Rio Grande do Sul, Departamento de Metalurgia, Centro de Tecnologia, \\ Laboratório de Transformação Mecânica, Porto Alegre, RS, Brasil \\ ${ }^{b}$ Instituto Federal de Educação, Ciência e Tecnologia (IFSUL), Sapucaia do Sul, RS, Brasil \\ ${ }^{c}$ Leibniz-Institut für Werkstofforientierte Technologien (IWT), Bremen, Germany \\ ${ }^{d}$ University of Bremen, MAPEX Centre for Materials and Processes, Bremen, Germany
}

Received: June 19, 2020; Revised: September 08, 2020; Accepted: September 19, 2020

It is well recognized the importance of the rheological characterization for the development of the steel in thermomechanical treatments, especially for the mechanical properties improvement of bainitic steels in subsequent hot forging optimization. Therefore, the plastic strain behaviour of a low carbon high silicon bainitic steel was studied through isothermal compression tests using a thermomechanical simulator at temperatures of $1123 \mathrm{~K}-1423 \mathrm{~K}$ and strain rates of $0.1-5 \mathrm{~s}^{-1}$. Arrhenius equation was used to obtain the constitutive constants, which represents the material behaviour of flow stress in high temperature. Besides, work hardening, dynamic recovery, and the JMAK model in the dynamic recrystallization (DRX) of the steel parameters were determined. The second part of this research compared two proposed modified models from the literature, which showed the differences in modelled flow curves behaviour when they are applied for high strain levels. The flow curves were modelled in high strain levels for further implementation in numerical simulation, thus allowing an adjustment of parameters in hot forming processes for this bainitic steel. The proposed models presented an agreement with experimental values. However, only the Avrami equation to DRX showed the dynamic recovery mechanism in high strain levels, which has represented physical behaviour during the thermomechanical process.

Keywords: Flow Curves Modelling, Dynamic revorery and Dynamic recrystallization Kinetics, Bainitic Steels.

\section{Introduction}

Applications of advanced continuous cooling bainitic steels have received extensive attention in the past of decade due to their mechanical properties which can reach high levels of tensile strength and energy absorption. As a consequence, it has a considerable interest in industrial applications such as gears, crankshafts, side doors, railways and chassis ${ }^{1-3}$.

There is a continuous challenge for discovering the best parameters to reach outstanding mechanical properties with lower energy consumption. For that reason, this shortcoming can be improved by microstructure optimization, avoiding subsequent heat treatments. Thereby, the microstructure can be influenced by grain refining mechanisms, which brings different bainitic morphologies after continuous cooling ${ }^{4}$.

Consequently, the determination of steel's flow curves is essential for proper identification of process windows and to guarantee good mechanical properties of the final products. They also provide data that will bring technical support to forging factories, which produce a large proportion of components in the automotive industry. Therefore, efforts concerning the hot-working conditions such as a dependence of flow stress with dynamic recovery (DRV), dynamic

*e-mail: thiago.ivaniski@ufrgs.br recrystallization (DRX) plays an essential role regarding the interactions of applied process parameters. Thus, the application Arrhenius-type model for flow curves and JohnsonMehl-Avrami-Kolmogorov (JMAK) for recrystallization kinetics are indispensable. JMAK kinetics has a consolidated application in phase transformation of precipitation through nucleation and growth, which gives the content of a new phase as a function of time $e^{5-7}$. The global kinetics has been applied in the industrial field of hot forging steels because it represents a "semi-empirical" method, the numerical simulation results of the dynamically recrystallized volume fraction and austenitic grain size $\mathrm{e}^{8-10}$. Besides, in terms of the flow curves, it can be used to model the softening mechanism during the plastic deformation in metallic materials $\mathrm{s}^{6,7}$.

In previous researches, constitutive flow curves and microstructural models have been proposed for different bainitic steel grades, such as DIN 29MnSiCrAlNiMo, considered as a low carbon $\left(0.3\right.$ wt. $\%$ C) bainitic steel ${ }^{11}$. Also, the flow curves and microstructure evolution by JMAK approach of DIN 70MnCrSiMo carbide-free bainitic steel, containing a higher carbon amount of $0.7 \% \mathrm{C}$ studied by Han et al. ${ }^{12}$. They have reported as well in ${ }^{13}$, the effect of temperature and strain rate on dynamic recrystallization of the $0.5 \% \mathrm{C}$ bainitic steel. It was developed accurately a 
kinetic model which reflects the dynamically recrystallized volume fraction (XDRX) changes.

A critical characteristic of the presented material which differs from the others studied bainitic steels, is the low carbon content, below $0.2 \%$ C. Also, it is already known in recent reports that the continuous cooling of DIN 18MnCrSiMo6-4 bainitic steel has a suitable amount of silicon $(>1.0 \%)$ used to avoid cementite precipitation which is replaced by stabilized austenite as the second constituent in bainite $^{4}$. Thus, offering a considerable increase in yield strength and ductility. Moreover, the thermomechanical processing does not change the maximum attainable fraction of bainite, but clearly refines the microestruture after the austenite plastic deformation due to recrystallization mechanism ${ }^{14}$. However, there is still lacking information regarding different hot working conditions, which is essential to obtain input data to Finite Element Models, including DRX microstructure evolution-in this way, optimizing the production of hot forged components.

In order to study how this material behaves in hot work conditions, this paper aim at obtaining flow curves in isothermal compression tests at different temperatures and strain rates.

Mathematical models were applied to obtain the constitutive constants of (DRV) and dynamic recrystallization (DRX). Moreover, two modified models presented by Xiao and Guo $^{15}$, and Mirzadeh and Najafizadeh ${ }^{16}$, which include the Avrami-type equation, were used in this work. This equation has taken in to account the softening mechanism caused by the DRX in high-temperature plastic strain ${ }^{17}$. Both models were extrapolated for high plastic strain levels and compared with the experimental results.

\section{Experimental Procedures}

Table 1 shows the chemical composition of the low carbon bainitic steel DIN 18MnCrSiMo6-4, which was developed and produced by the Swisstec (Swiss Steel), Emmenbrücke, Switzerland. Figure 1 shows the as-received microstructure composed by Granular Bainite (GB), which is characterized by Bainitic Ferrite (White Regions), Retained Austenite (RA) and Polygonal Ferrite (PF) 4 .

Compression tests in a DIL 805A/T dilatometer of TA instruments were implemented in order to obtain flow curves that represent material's behaviour in hot forming conditions. The parameters choice of testing is typical for hot forging using hydraulic and friction presses ${ }^{18}$.

The specimens were cylinders with a height of $10 \mathrm{~mm}$ and a diameter of $5 \mathrm{~mm}$. Figure 2 shows representative values of the temperature versus time cycle and the main steps in the hot compression tests. The deformation was carried out at temperatures ranging from $1123 \mathrm{~K}$ to $1423 \mathrm{~K}$ with an interval of $100 \mathrm{~K}$ and strain rates of $0.1 \mathrm{~s}^{-1}, 0.5 \mathrm{~s}^{-1}$, $1 \mathrm{~s}^{-1}$ and $5 \mathrm{~s}^{-1}$. The average heating rate and cooling rate was $10 \mathrm{~K} / \mathrm{s}$ and $50 \mathrm{~K} / \mathrm{s}$, respectively.
The samples were heated in a vacuum atmosphere until reaching the chosen temperature. Then, they were kept at this temperature during $300 \mathrm{~s}$ (soaking time), before compressive deformation begins. After compression, the samples were quenched instantaneously by an inert gas flow. In order to reduce friction effects, a tantalum foil was placed at the interface formed by sample and die. The correction for friction effects on flow curves was made according to Han et al ${ }^{9}$., and the Equation 1 shows flow stress data formulation to attained the frictionless effect.

$$
\bar{\sigma}=\frac{\sigma}{1+\left(\frac{2}{3 \sqrt{3}}\right) m\left(\frac{r_{0}}{h_{0}}\right) \exp \left(\frac{3 \varepsilon}{2}\right)}
$$

Where, $\bar{\sigma}$ is the corrected flow stress, $\sigma$ is the measured flow stress given in (MPa), $\varepsilon$ is the measured strain, $r_{0}$ and $h_{0}$ is initial radius and height in $(\mathrm{mm})$ respectively, finaly $m$ represent the friction factor. Behind of $m$ value results for each flow stress, there are relations which is calculed only by measuring of the maximum radius, $R m$, and the calculation of the height after the plastic deformation. Detailed formulation and explanation of the procedure can be consulted $\mathrm{in}^{19}$.

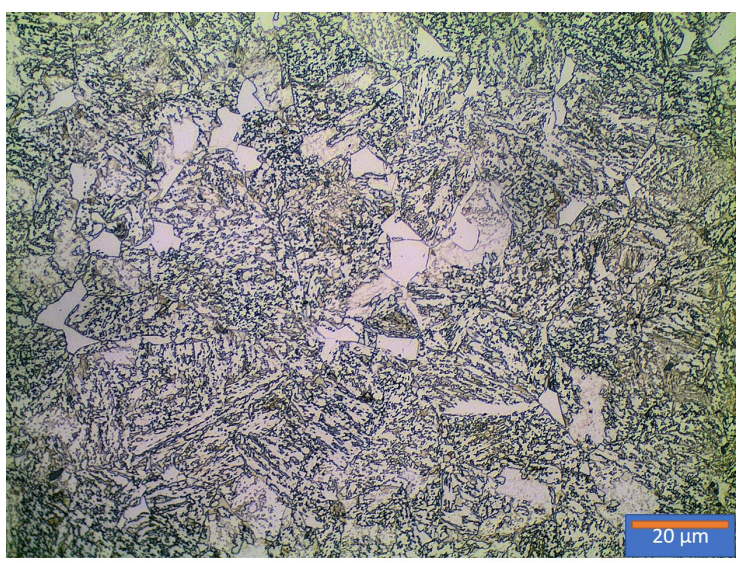

Figure 1. As-received microstructure revealed by optical microscopy of the DIN 18MnCrSiMo6-4.

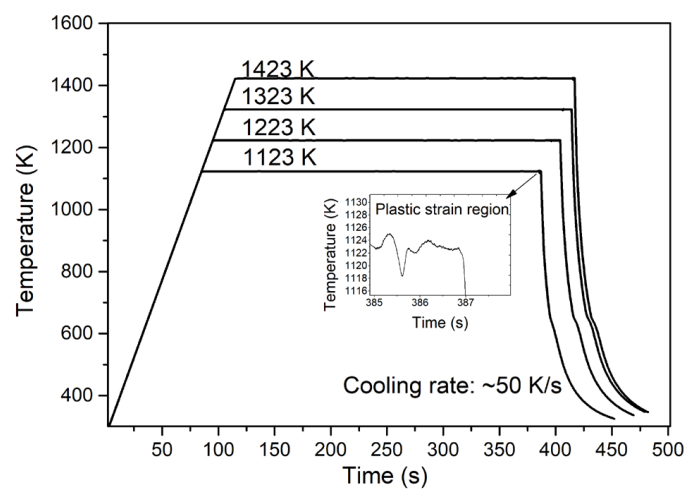

Figure 2. Representation of the hot compression tests.

Table 1. Chemical composition of the experimental DIN 18MnCrSiMo6-4.

\begin{tabular}{ccccccccccccc}
\hline Element & $\mathbf{C}$ & $\mathbf{S i}$ & $\mathbf{M n}$ & $\mathbf{S}$ & $\mathbf{N i}$ & $\mathbf{C r}$ & $\mathbf{C u}$ & $\mathbf{M o}$ & $\mathbf{A l}$ & $\mathbf{T i}$ & $\mathbf{N}$ & $\mathbf{F e}$ \\
\hline wt. $\%$ & 0.18 & 1.19 & 1.42 & 0.015 & 0.063 & 1.17 & 0.10 & 0.27 & 0.005 & 0.004 & 0.01 & Bal. \\
\hline
\end{tabular}




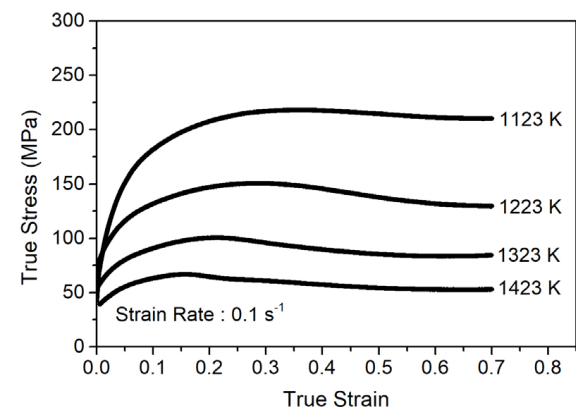

(a)

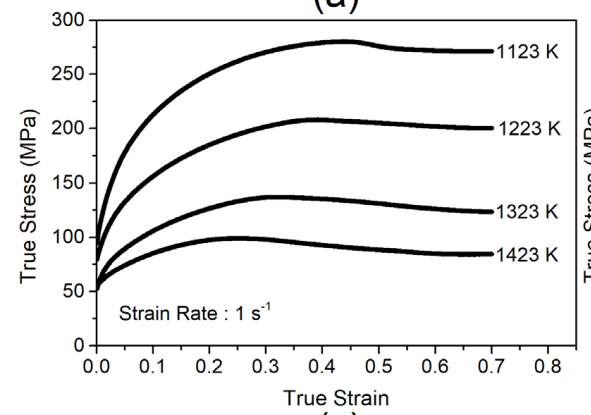

(c)

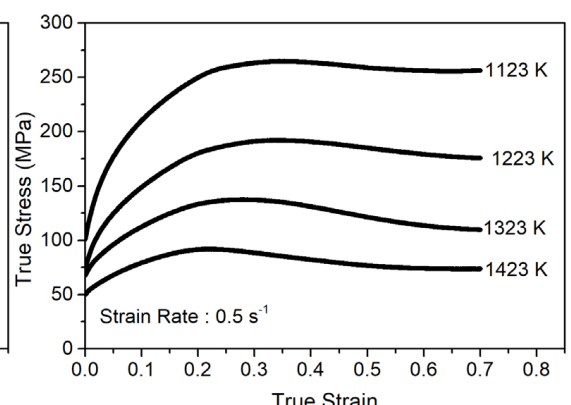

(b)

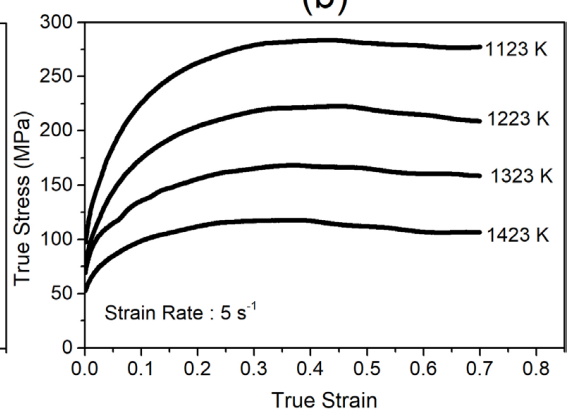

(d)

Figure 3. True Stress versus True Strain curves of studied steel at four different strain rates and temperatures (a) $0.1 \mathrm{~s}^{-1}$, (b) $0.5 \mathrm{~s}^{-1}$, (c) $1 \mathrm{~s}^{-1}$, (d) $5 \mathrm{~s}^{-1}$.

\section{Results and Discussion}

\subsection{Flow curves}

Figure 3 shows the resulting flow stress curves of steel obtained from the hot compression tests at the four different temperatures (from $1123 \mathrm{~K}$ to $1423 \mathrm{~K}$ ) and strain rates ( from $0.1 \mathrm{~s}^{-1}$ to $5 \mathrm{~s}^{-1}$ ). The mean flow stress decreases with temperature increase for the same strain rate and, higher stress gradient can be seen as proportional to applied strain rates, when they are compared at the same temperatures.

The activation of dynamic softening is higher when temperature increases in overall curves. However, the gradient between the peak stress and steady-state at the same temperature, decreases at higher strain rates, as one can see by comparing Figure 3a and Figure 3d. For the lowest temperature, $1123 \mathrm{~K}$, the maximum stress level variation is lower at all strain rates when compared to the temperature of $1423 \mathrm{~K}$, the highest one.

Figure 4 shows the surface plot of the strain rate sensitivity variations (Equation 2) ${ }^{18}$ according to the different strain rate and temperature levels. This behaviour indicates a reduction of strain rate sensitivity $\left({ }^{\omega}\right)$ with the temperature, which represents lower dislocation mobility during plastic deformation.

$\omega=\frac{\partial \log (\sigma)}{\partial \log (\dot{\varepsilon})_{T, \varepsilon}}$

In summary, the flow stress for this steel can be divided into three stages, which correspond to work hardening $(W H)$, dynamic softening and steady-state stress. The $(W H)$, first stage, represents a rapid increase of the material strength

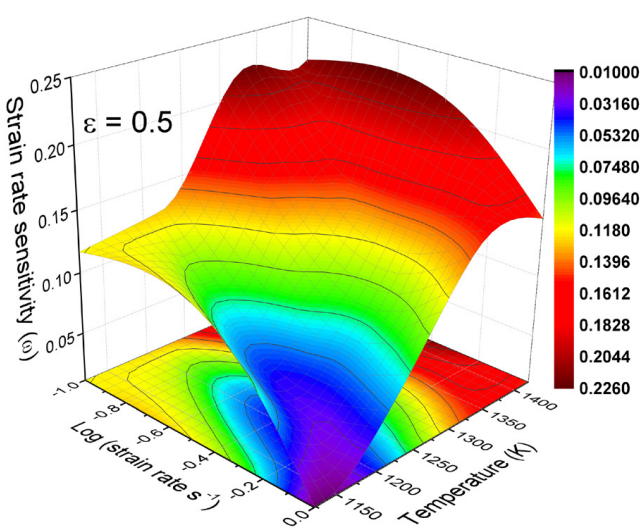

Figure 4. Surface plot of the effect of strain rate and temperature on the strain rate sensitivity at 0.5 of plastic deformation.

due to the accumulation of dislocation and the piling up by barriers, which is increasing with the strain rate $e^{7,20}$. The dynamic softening is characterized by the appearance of a second peak in the flow curve, in the second stage of deformation. Hence, the dynamic softening mechanisms occur due to the annihilation and rearrangement of mobile dislocation, demonstrating a $D R X$ characteristic behaviour ${ }^{12}$. The dynamic balance in the dislocations remained constants when the flow curves achieved the third stage and the stress, which is represented in that point the steady-state stress.

\subsection{Parametrization of Arhenius equation}

Flow stress and dynamic recrystallization kinect were modelled based on equations for low alloy and microalloyed steels as given by ${ }^{7,20,21}$ where the work-hardening 
and dynamic recovery have been taken into account. In the flow softening behaviour, the Zener-Hollomon parameter (Z) Equation 3, representing the strain rate factor in $\left(\mathrm{s}^{-1}\right)$, compensated by temperature.

Arrhenius-type equation, which represents the correlation between flow stress $(\sigma)$, temperature and strain rate are available as given in Equation 4 and Equation 5 for lower stress level. The Equation 6 is applied for higher stress levels and for overall stress ${ }^{13}$.

Applying natural logarithms of Equation 4, Equation 5 and Equation 6, based on experimental data plotted in Figure 5a, the coefficient $n$ ' is 6.3858, was obtained trhough the mean of the linear fits of $\log \sigma-\log \dot{\varepsilon}$ in different temperatures. The mean $\beta$ value obtained by the linear fit, presented in Figure $5 \mathrm{~b}$ is 0.06283 . Therefore, $\alpha$ is the material parameter regulating the peak stress $\left(\mathrm{MPa}^{-1}\right)$, can be calculated by $\alpha=\beta / n^{\prime}=0.009838$.

Correlations were established based on these equations to determine the constants $\alpha, \mathrm{n}, \mathrm{n}$ ' $\mathrm{Q}$ and $A^{\prime}, A^{\prime \prime}, A$, for the peak flow stress $\left(\sigma_{p}\right)$ and steady- state stress $\left(\sigma_{s s}\right)$ into determined strain.

$$
\begin{aligned}
& Z=\dot{\varepsilon} \exp ^{\left(\frac{Q}{R T}\right)} \\
& A^{\prime} \sigma^{n^{\prime}}=f(\sigma)=\frac{\dot{\varepsilon}}{A} \exp ^{\left(\frac{Q}{R T}\right)} \\
& A^{\prime \prime} \exp (\beta \sigma)=f(\sigma)=\frac{\dot{\varepsilon}}{A} \exp ^{\left(\frac{Q}{R T}\right)} \\
& {\left[\sinh \left(\alpha \sigma_{p}\right)\right]^{n}=\frac{Z}{A}=\frac{\dot{\varepsilon}}{A} \exp ^{\left(\frac{Q}{R T}\right)}}
\end{aligned}
$$

Where $\dot{\varepsilon}$ is the strain rate $\left(\mathrm{s}^{-1}\right), n$ represent the stress exponent, $A$ is a material constant, $Q$ the activation energy $\left(\mathrm{J} \cdot \mathrm{mol}^{-1}\right)$ and $\mathrm{R}$ is the universal gas constant $\left(8.314 \mathrm{~J} \cdot \mathrm{mol}^{-1} \cdot \mathrm{k}^{-1}\right)$ multiplied by the absolute temperature in Kelvin (K). The Eq. 7 is used to determine $(Q)^{11,19,22}$.

$Q=R n\left[\frac{\partial \log \left[\sinh \left(\alpha \sigma_{p}\right)\right]}{\partial\left(\frac{1}{T}\right)}\right]$

After obtaining the coefficients $\alpha, \mathrm{n}, \beta$ and $Q$ it was possible to determine the mean value of the coefficient $A$, and taking the logarithm of Equation 8 the equation Equation 9 was obtained. Figure 6 shows the relationship between $\log [\sinh (\alpha \sigma)]$ and $\log Z$ which presents a good correlation for the data plot, therefore, $\log A$ can be found by the interception of the curve. Finally, an average of the material constant $A$ is defined as $7.61 \times 10^{11}$.

$\log Z=\log A+n \log [\sinh (\alpha \sigma)]$

As a result, the Zener-Hollomon $Z$ in $\left(\mathrm{s}^{-1}\right)$ equation for the steel can be described as follows:

$$
\dot{\varepsilon}=7.61 \times 10^{11}\left[\sinh \left(0.009838 \sigma_{p}\right)\right]^{5.179} \exp \left(\frac{-276684}{R T}\right)
$$

\subsection{Determination of recovery $(D R V)$ and $(D R X)$ parameters $\left(\sigma_{W H}, \sigma_{s a t}, \sigma_{p}, \sigma_{c}, \sigma_{s s}, \varepsilon_{c}, \varepsilon_{p}\right)$}

Dislocation density $\rho$ dependency on plastic strain $\varepsilon$ is considered by Estrin and Mecking approach ${ }^{23}$ and are described in Equation 10. Where $(h)$ represents the athermal coefficient of work hardening and, $r$ is the coefficient of dynamic-recovery when the strain $\varepsilon=0, \rho=\rho_{0}$, where $\rho_{0}$ represents the initial dislocation density. The ratio of $h / r$

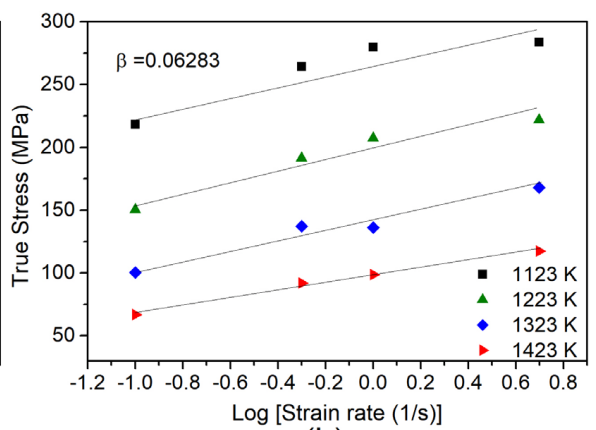

(b)

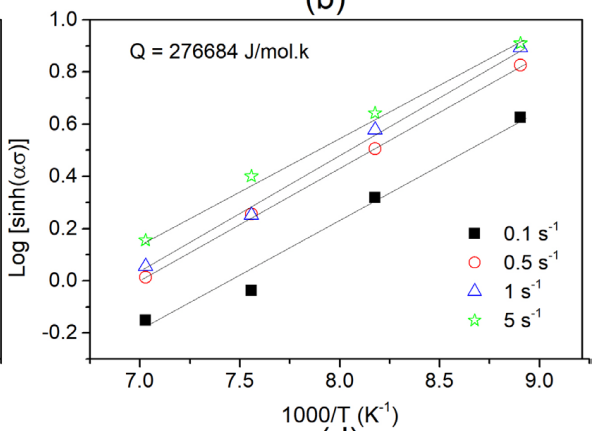

(d)

Figure 5. Peak stress and peak strain relationship to determine the coefficients: (a) $n$, (b) $\beta$, (c) $n$, (d) $Q$. 
is used to define $\sigma_{\text {sat }}$, details concerning the equations used in this work can be consulted in ${ }^{7}$. The work hardening rate method $\left(\theta=\frac{\partial \sigma}{\partial \varepsilon}\right)$ was used in this work to determine these parameters from the flow curves ${ }^{11}$.

$$
\frac{\partial \rho}{\partial \varepsilon}=h-r \rho
$$

The results lead to the following equation, Equation 11, giving the work hardening stress $\left(\sigma_{W H}\right)$ at the beginning of the compression test and Equation 12 describing the overall flow curve:

$$
\begin{aligned}
& \sigma_{W H}=\left(\sigma_{\text {sat }}^{2}-\left(\sigma_{\text {sat }}^{2}-\sigma_{0}^{2}\right) \exp (-r \varepsilon)\right)^{1 / 2} \\
& \sigma \frac{\partial \sigma}{\partial \varepsilon}=0.5 r \sigma_{\text {sat }}^{2}-0.5 r \sigma^{2}
\end{aligned}
$$

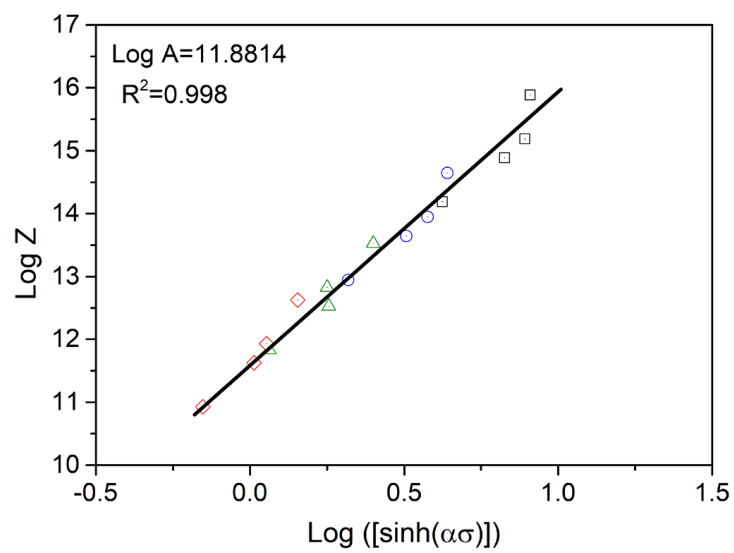

Figure 6. Linear correlation between $\log [\sinh (\alpha \sigma)]$ and $\log Z$ under different hot work conditions for the bainitic steel.

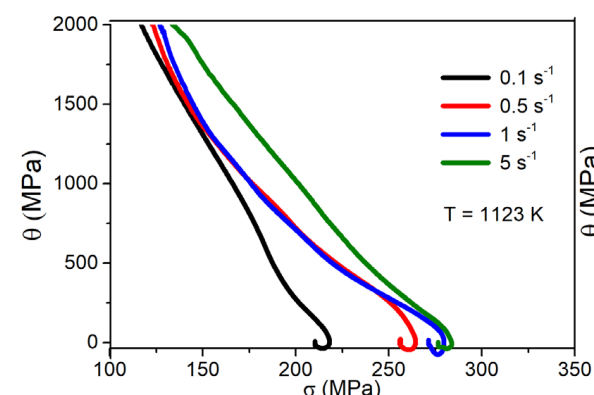

(a)

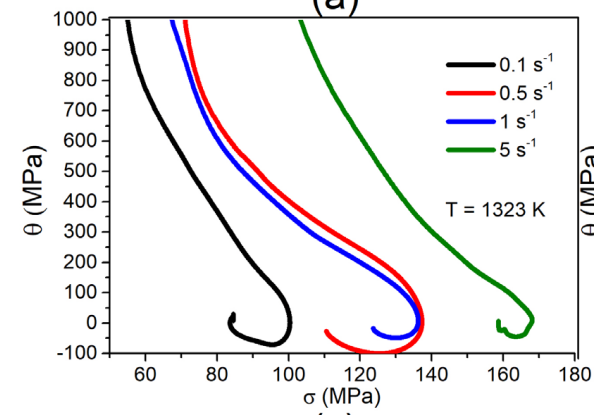

(c)
Where $\left(\sigma_{\text {sat }}\right)$ is the saturation stress during the hot working conditions.

Figure 7 shows the specific curvature of the first derivation of work hardening used to determine the $r$-coefficient, which generates the curve calculated by $\theta \sigma$ and plotted as a function of the stress $\sigma^{2}$, as can be seen in the example of Figure 8 . The slope $m$ of tangent was used by $\mathrm{b}^{7,22}$ to determine the $r$ value $(r=-2 m)$.

Table 2 shows that $r$ value has a decreasing tendence when the peak stress increase. Moreover, higher values of $r$ lead the material to develop a saturation stress $\left(\sigma_{\text {sat }}\right)$ more quickly.

The high $r$-value is associated with the moderate stacking fault energy (SFE) value of the material, which makes thermomechanically activated mechanisms difficult ${ }^{24}$. This makes dynamic recovery more active during the process, delaying dynamic recrystallization kinetics. According to ${ }^{7}$, the addition of alloying elements has a reasonable effect on these parameters changing with strain rate increase. For the DIN 18MnCrSiMo6-4 bainitic steel, in defined contitions of hot working, the $r$-value is between 6 and 18 .

To evaluate the $h$ - parameter associated with each presented flow curve, the Equation 13 was used.

$h=r_{|T \dot{\varepsilon}|} \frac{\sigma_{s a t|T \dot{\varepsilon}|}^{2}}{(\alpha \mu b)^{2}}$

Where $\mu$ is the shear modulus, which was considered $36.06 \mathrm{GPa}$, according to ${ }^{7}$. The constant $b$ is the magnitude of Burgers vector of dislocation of austenite, in this work is equal to $0.3606858 \mathrm{~nm}$, according to the equation proposed by ${ }^{25}$.

As a result, Figure 9b displays the variation of athermal work hardening parameter $h$ for different peak stresses. It can be observed that $h$ - parameter increases linearly with the peak stress. The parameter $h$-parameter can be interpreted

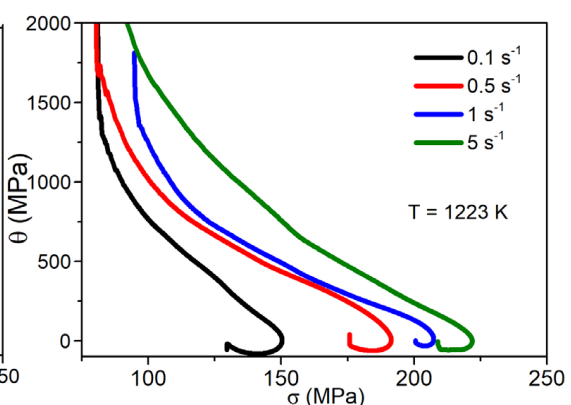

(b)

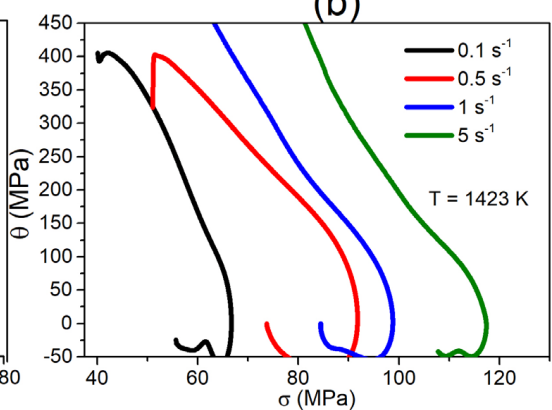

(d)

Figure 7. $\theta-\sigma$ curves on different temperatures and strain rates: (a) $1123 \mathrm{~K}$; (b) $1223 \mathrm{~K}$; (c) $1323 \mathrm{~K}$; (d) $1423 \mathrm{~K}$. 
Table 2. Dynamic recovery parameter $(r)$ obtained from the flow curves of DIN 18MnCrSiMo6-4.

\begin{tabular}{cccccc}
\hline Temperature (K) & DRV Parameter $r(-)$ & $\begin{array}{c}\text { Peak Stress } \\
\sigma_{p}(M P a)\end{array}$ & $\begin{array}{c}\text { Saturation stress } \\
\sigma_{\text {sat }}(M P a)\end{array}$ & Strain rate $\dot{\varepsilon}\left(s^{-1}\right)$ & $\begin{array}{c}\text { Zener Parameter Z } \\
\left(s^{-1}\right)\end{array}$ \\
\hline 1123 & $\mathbf{1 8 . 3 9 1 8}$ & 218.1109 & 222.7409257 & 0.1 & $1.54282 \mathrm{E}+14$ \\
\hline 1223 & $\mathbf{9 . 6 6 2 8 4}$ & 264.395 & 281.9367837 & 0.5 & $7.71412 \mathrm{E}+14$ \\
\hline 1323 & $\mathbf{7 . 9 3 2 6}$ & 279.68 & 292.970647 & 1 & $1.54282 \mathrm{E}+15$ \\
\hline 1423 & $\mathbf{9 . 8 0 4}$ & 283.74 & 293.211596 & 5 & $7.71412 \mathrm{E}+15$ \\
\hline 1123 & $\mathbf{1 9 . 5 4}$ & 150.33627 & 153.0959121 & 0.1 & $8.83948 \mathrm{E}+12$ \\
\hline 1223 & $\mathbf{6 . 9}$ & 191.3793 & 211.6737081 & 0.5 & $4.41974 \mathrm{E}+13$ \\
\hline 1323 & $\mathbf{5 . 9}$ & 207.28417 & 223.8875164 & 1 & $8.83948 \mathrm{E}+13$ \\
\hline 1423 & $\mathbf{7 . 8 8}$ & 221.8566 & 228.984113 & 5 & $4.41974 \mathrm{E}+14$ \\
\hline 1123 & $\mathbf{1 2 . 8 6}$ & 100.39 & 104.6984241 & 0.1 & $6.74686 \mathrm{E}+11$ \\
\hline 1223 & $\mathbf{6 . 1 4}$ & 137.2563 & 157.6362173 & 0.5 & $3.37343 \mathrm{E}+12$ \\
\hline 1323 & $\mathbf{6 . 1}$ & 136.1869 & 151.4524348 & 1 & $6.74686 \mathrm{E}+12$ \\
\hline 1423 & $\mathbf{1 1 . 2 4}$ & 167.88 & 171.2639858 & 5 & $3.37343 \mathrm{E}+13$ \\
\hline 1123 & $\mathbf{1 3 . 1 8}$ & 66.67 & 71.02664711 & 0.1 & 84634659177 \\
\hline 1223 & $\mathbf{7 . 3 4}$ & 91.77 & 113.8972212 & 0.5 & $4.23173 \mathrm{E}+11$ \\
\hline 1323 & $\mathbf{7 . 5 2}$ & 98.78 & 108.410065 & 1 & $8.46347 \mathrm{E}+11$ \\
\hline 1423 & $\mathbf{9 . 1 4}$ & 117.37 & 121.586857 & 5 & $4.23173 \mathrm{E}+12$ \\
\hline
\end{tabular}

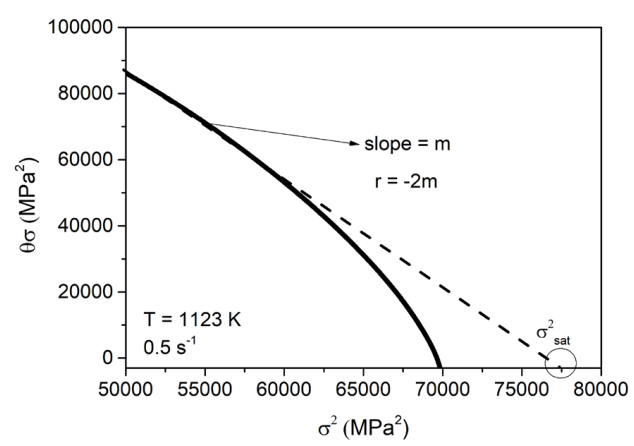

Figure 8. Plot of $\theta \sigma$ vs. $\sigma^{2}$ employed to determine the slope $\mathrm{m}$ for the steel at different temperatures and strain rates.

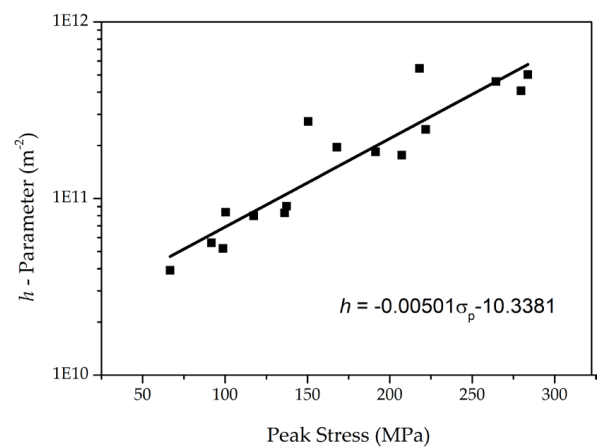

Figure 9. Athermal work hardening $(h)$ as a function of peak stress for DIN 18MnCrSiMo6-4 steel.

as the mean free path of the dislocations during the plastic strain at the flow curves ${ }^{7}$.

Figure 10a shows the relationship between critical stress, peak stress, critical strain and peak strain $\left(\sigma_{p}, \sigma_{c}, \varepsilon_{c}, \varepsilon_{p}\right)$ respectively, and Figure $10 \mathrm{~b}$ the relation of steady-state stress and Z parameter. It can be noted that there is a linear relationship between the plotted values. As the strain rate increases, the corresponding $h$-parameter increase. Therefore, the equations describing the critical strains and peak strain $\varepsilon_{c}$, and $\varepsilon_{p}$ for the investigated material, can be written:

$$
\begin{aligned}
& \varepsilon_{c}=0.002375 Z^{0.138275} \\
& \varepsilon_{p}=0.0017575 Z^{0.118425}
\end{aligned}
$$

For the critical and the peak stress $\sigma_{c}$ and $\sigma_{p}$ :

$$
\begin{aligned}
& \sigma_{c}=6.095475 Z^{0.1138} \\
& \sigma_{p}=9.522275 Z^{0.10955}
\end{aligned}
$$

These values play an essential role to represent the critical condition for initiation of DRX, while the steady-state stress $\sigma_{s s}$ is related to the competition between dislocation generation and dynamic recovery at hot deformation contitions. Both increase when $\mathrm{Z}$ value increases in a linear correlation, therefore the ratio of $\sigma_{p} / \sigma_{c}$ is about 0.974 and $\varepsilon_{c} / \varepsilon_{p} 0.54$.

Peak flow stress $\left(\sigma_{p}\right)$ which is set as a reference to derive the flow stress at any strain ranging from approximately 0 to 0.7 , is calculed from the acquired coefficients, and can be described by Equation 18.

$$
\sigma_{p}=\frac{1}{\alpha} \ln \left[\left(\frac{Z}{A}\right)^{1 / n}+\sqrt{\left(\frac{Z}{A}\right)^{2 / n}+1}\right]
$$

Therefore, the general equation can be presented in Equation 19 for the DIN 18MnCrMoSi6-4 bainitic steel during the hot compression tests, after all, regression analysis.

$$
\sigma_{p}=\frac{1}{0.0098} \ln \left[\left(\frac{Z}{7.61 \cdot 10^{11}}\right)^{0.1934}+\sqrt{\left(\frac{Z}{7.61 \cdot 10^{11}}\right)^{0.3868}+1}\right]
$$

\subsection{Analysis of the Dynamic Recrystallization DRX Kinetics}

The softened fraction $(\mathrm{X})$ is presented in Equation 20, at any point in the process, is described by the ratio between the differences of DRV and DRX. Where $\sigma_{W H}$ is the stress at a 


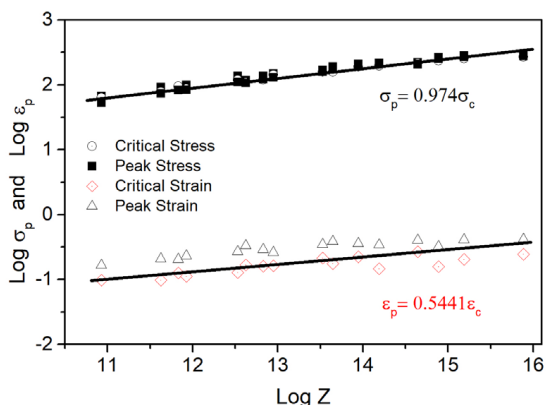

(a)

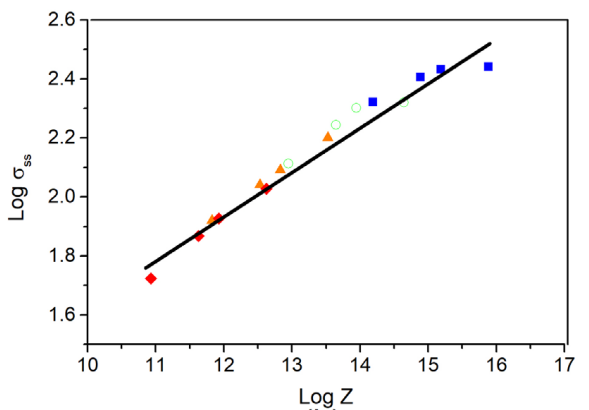

(b)

Figure 10. Linear relationship between (a) $\sigma_{p}, \sigma_{c}, \varepsilon_{c}, \varepsilon_{p}$. and (b) Steady-state stress for Z parameter.

specific strain given by Equation 11, and $\sigma_{\text {sat }}$ comes from the square root of the tangent of work hardening showed in Figure 8.

$$
X_{D R X}=\frac{\sigma_{W H}-\sigma}{\sigma_{s a t}-\sigma_{s s}}
$$

A consolidate description of DRX kinetics based on the JMAK phenomenological equation, was employed in the present work is indicated by Equation 21.

$$
X_{D R X}=1-\exp \left[-b\left(\frac{\varepsilon-\varepsilon_{c}}{\varepsilon_{p}}\right)^{\tau}\right]
$$

The exponent (b) represents the Avrami coefficient, therefore it is sensitive to variations in temperature while, the Avrami exponent $(\tau)$ is related to the mechanism of phase transformation. Thereby, combining Equation 20 and Equation 21, and taking natural logarithm on the kinetic model of DRX can give Equation 22.

$$
\operatorname{Ln} \cdot \operatorname{Ln}\left(\frac{1}{X}\right)=\operatorname{Lnb}+n \operatorname{Ln}\left(\frac{\varepsilon-\varepsilon_{c}}{\varepsilon_{p}}\right)
$$

As a result of the substitution of obtained values $\left(\sigma_{W H}, \sigma_{s a t}, \sigma_{p}, \sigma_{s s}, \varepsilon_{c}, \varepsilon_{p}\right)$ under all process conditions into Equation 19, the Avrami coefficient $(n)$ and exponent (b) can be found by linear regression at different levels of strain rate and temperature. All the softening data from the flow curves were converted into time (s) format using the ratio between the strain and strain rate $\left(\mathrm{s}^{-1}\right)$ as presented in Equation $23^{7}$. Figure 11 displays the JMAK plot for the steel in different temperatures. As mentioned by ${ }^{7}$, when increasing the temperature, the kinetics rises the softening rate during the plastic deformation.

$t=\left(\frac{\varepsilon-\varepsilon_{c}}{\dot{\varepsilon}}\right)$

The slope of the curves gives the Avrami's exponent, which decreases according to the reduction in temperature, as can be seen in Figure 11. After a series of adjustments in different temperatures and strain rates, it was verified that the average value of the coefficients $(b)$ and $(n)$ are 0.597 and 1.798 , respectively. Equation 24 shows the JMAK equation for DIN 18MnCrSiMo6-4 bainitic steel:

$$
X_{D R X}=1-\exp \left[\left(-0.597\left(\frac{t}{t_{0.5}}\right)\right)^{1.798}\right]
$$

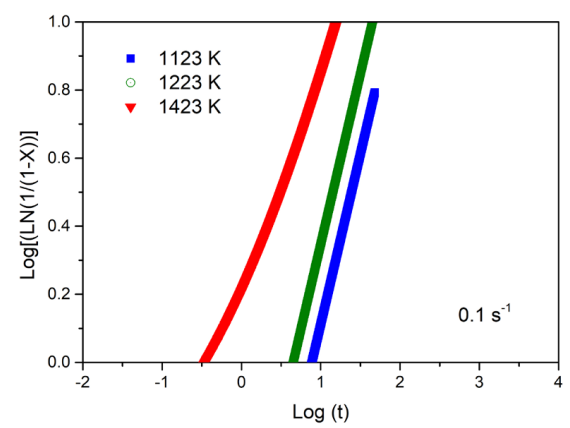

Figure 11. JMAK plot for $18 \mathrm{MnCrSiMo6}-4$ during the hot compression showing the effect of the temperature in the softening rate.

Where $t_{0.5}$ is 6

$$
t_{0.5}=A^{\prime} Z^{-q} d_{o}^{v} \exp \left(\frac{Q}{R T}\right)
$$

The coefficient $(b)$ and $(n)$ are close to the values found in the literature ${ }^{11}$ for high carbon silicon-rich bainitic steels. Parameters $q$ and $v$ are considered as 0.4 and 2 respectively, according to ${ }^{7}$. Figure $12 \mathrm{a}$ and Figure $12 \mathrm{~b}$ represents two possibilities of the time reduction for the complete recrystallization mechanism, one when increasing the temperature and other due to the high strain rate levels.

Hence, the time required for $50 \%$ of the softened fraction to occur during deformation depends on both process condition. The value of $t_{0.5}$ decreases with the increase in temperature and has a considerable influence on the strain rate. It is known that high strain rates increase the driving force for nucleation mechanisms to occur during dynamic recrystallization ${ }^{8,11,16}$. Therefore, the increase of migration rate of dislocations and grain boundaries is one of the consequences of accelerating the DRX process. It can be observed in Figure 12b, that at the higher strain rates, there is no time available for the new recrystallized grains to grow up and therefore a finer grain size is expected ${ }^{11,16}$.

\subsection{Modelling flow curves}

After the acquisition of all the coefficients necessary to obtain the parameters of work hardening, dynamic recrystallization and dynamic recovery, the models proposed by ${ }^{15}$ and $^{16}$ were applied. It was compared the accuracy of the proposed flow curves model for bainitic steel. The flow curves were modeled taking into account higher plastic deformation values for two models. 
The mode ${ }^{15}$ considers, the effect of plastic strain temperature as well as the strain rate based on the Arrehnius model. They are represented by the Zener-Hollomon parameter, as given in Equation 26:

$$
\sigma_{\text {modI }}=\frac{k_{0}}{\alpha} \varepsilon^{k_{1}} \exp \left(-k_{2} \varepsilon\right) \sigma_{p}
$$

Where $k_{0}, k_{1}$ and $k_{2}$ are constants of the material, and the variation depending on the degree of plastic deformation and temperature as well as $\sigma_{p}$ is the peak stress from Equation 16. After linear regressions, a relation of these parameters was obtained with the Zener-Hollomom parameter, and they are presented in Equations 27, 28 and 29.

$k_{0}=3.17 \ln (Z)+0.12$

$k_{1}=0.02 \ln (Z)-0.09$

$$
k_{2}=0.05848 \ln (Z)+0.795
$$

These relations were compared with the Avrami-type model proposed by Laasraoui and Jonas ${ }^{26}$ and applied by ${ }^{16,17}$ in Equation 30, which takes into account the work-hardening, dynamic recrystallization and dynamic recovering parameters. Thereby, it is possible to extrapolate these flow curves for non-achievable laboratory parameter testing ${ }^{7,16}$, for example in hot forging processes for where the strain rates can reach values above $100 \mathrm{~s}^{-1}$ with screw presses, for example ${ }^{18}$.

$\sigma_{\text {mod } 2}=\sigma_{W H}-\left[\sigma_{s a t}-\sigma_{s s}\right]\left(1-\exp \left(-b\left(\frac{t}{t_{0.5}}\right)^{\tau}\right)\right.$

Figure 13 compares experimental plastic flow curves with those modelled analytically for different conditions of strain rate and temperature. It is noticeable that in general, there is a good agreement between the experimental results with the proposed

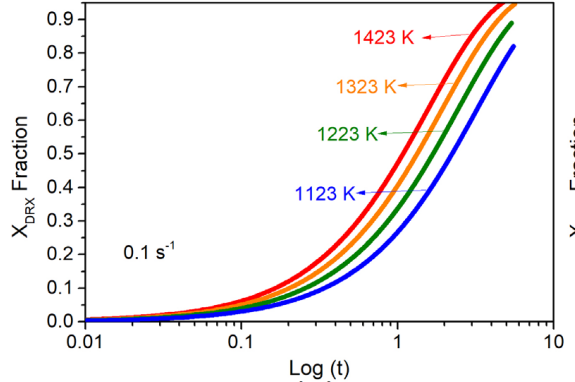

(a)

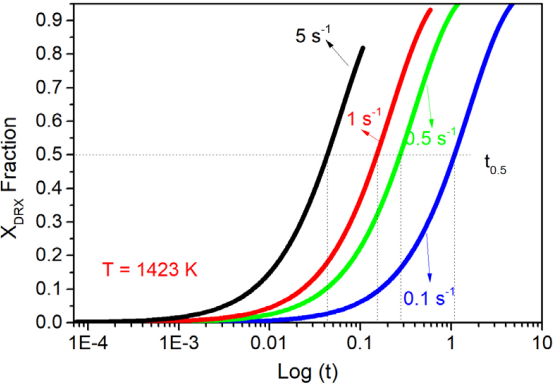

(b)

Figure 12. $\mathrm{X}_{\mathrm{DRX}}$ volume fraction of recrystallized grains during the hot working condition as a function of (a) Temperature, (b) Strain rate.
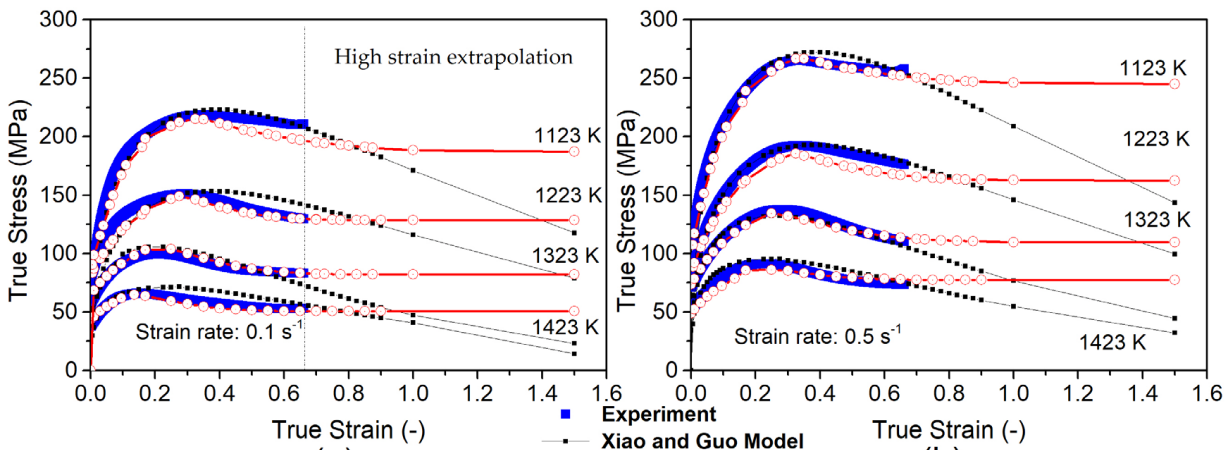

(a)

Xiao and Guo Model

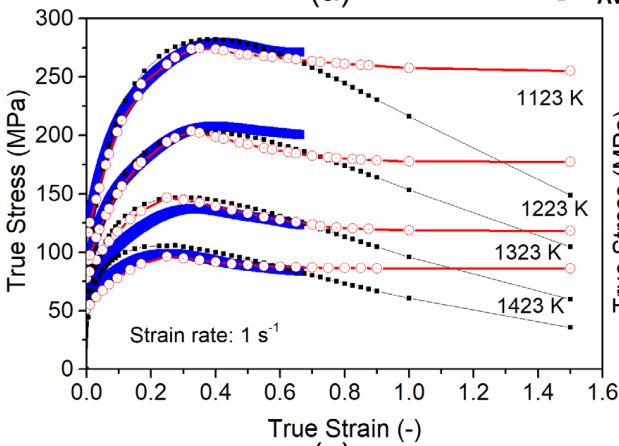

(c)

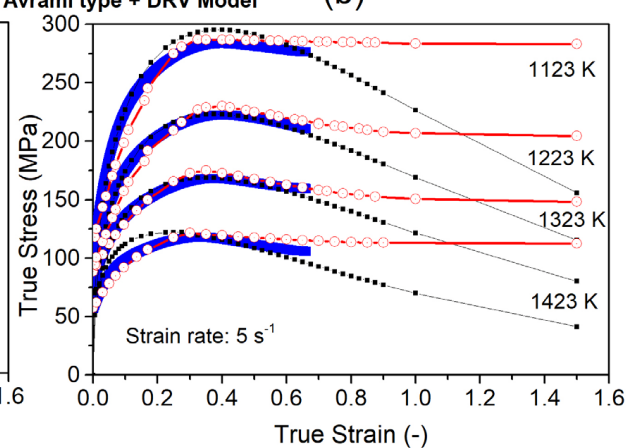

(d)

Figure 13. Comparison between experiment flow curves and the two different models with high strain extrapolation for the DIN $18 \mathrm{MnCrSiMo6}-4$ steel for different strain rates and temperatures, (a) Strain rate $0.1 \mathrm{~s}^{-1}$, (b) $0.5 \mathrm{~s}^{-1}$, (c) $1 \mathrm{~s}^{-1}$ and (d) $5 \mathrm{~s}^{-1}$. 
model by ${ }^{15}$, the combination of Equation 19 and Equation 26 and therefore, is possible to implement in numerical models.

However, the relation offered by ${ }^{15}$, for more considerable plastic strain tends to reach zero or even negative values which do not represent a physical behaviour when compared to the model proposed by ${ }^{16}$. Hence, to represent a real material flow after the stress dropping due to $D R X$ behaviour, the state saturations stress $\left(\sigma_{\text {sat }}\right)$ may be considered to remain constant at the steady-state stress $\left(\sigma_{s s}\right)$, which was better described by Avrami model given by Equation 30 .

\section{Conclusions}

This paper showed detailed investigations to experimentally determined and numerically model the flow curves of lowcarbon high silicon bainitic steel DIN 18MnCrSiMo6-4 in hot working conditions by the isothermal compression test. The following main conclusions were obtained:

1. Algebraic equations of the flow curves have been derivated of hyperbolic sine, which showed a linear behaviour with the Zener-Hollomon parameter. The general equation of the peak stress for the steel has been defined.

2. Dependence on the increase of dislocation density with the plastic deformation was taken into account during the plastic strain to model implementation. Therefore, the dynamic recovery parameters (DRV) were determined in the different process conditions, expanding the application for higher high strain rates than those achievable laboratory testing.

3. The parameters of JMAK equation governing behaviour during dynamic recrystallization for the specific steel under investigation were determined.

4. Finally, two different models were compared to experimentally obtained flow curves, and then used to extrapolate the results to higher strains. Both models gave a good approximation with the experimental values up to 0.69 of plastic strain. However, only the Avrami-Type model physically demonstrated the dynamic recovery behaviour remaining the stress constant for higher strain levels. Therefore, this model should be preferentially implemented in massive forming operation, which can lead to very high strain levels.

\section{Acknowledgements}

The authors acknowledge the Brazilian agency CAPES (Project 1844/2017) and the Deutsch Forschungsgemeinschaft (German Research Foundation - DFG) via project EP 128/6-2 (Project number 327887503) for the financial support within the BRAGECRIM program (Brazilian German Cooperation Research in Manufacturing). The authors also thanks the Metal Forming Institute IBF- RWTH Aachen in Germany for the support during experimental data acquisition. Thiago M. Ivaniski and Alexandre da S. Rocha also acknowledge CNPq (process numbers $167948 / 2017-2$ and 308773/2018-7) for the grants.

\section{References}

1. Bhadeshia HKDH, Gomez G, Pe T. Air cooled bainitic steels for strong, seamless pipes Part 2 - properties and microstructure of rolled material. Mater Sci Technol. 2009;25(12):1-5.
2. Caballero FG, Capdevila C, Chao J. The microstructure of continuously cooled tough bainitic steels. In: 2 nd International Conference of Super-High Strength Steels; 2010 Oct 1720; Peschiera del Garda, Verona, Italy. Proceedings. Itália: Associazione Italiana di Metallurgia; 2010. p. 10-18.

3. Roelofs H, Hasler S, Urlau U, Lembke MI, Olschewski G. Continuously cooled bainitic steel HSX ${ }^{\circledR}$ Z12: one decade of experience. In 4th International Conference on Steels in Cars and Trucks; 2014; Braunschweig, Germany. Proceedings. Düsseldorf: Stahleisen; 2014.

4. Silveira AC, Bevilaqua WL, Dias VW, de Castro PJ, Epp $\mathrm{J}$, Rocha AS. Influence of hot forging parameters on a low carbon continuous cooling bainitic steel microstructure. Metals (Basel). 2020;10(5):601.

5. Shkatov V, Mazur I. Modeling the dynamic recrystallization and flow curves using the kinetics of static recrystallization. Materials (Basel). 2019;12(18):3024.

6. Jorge AM Jr, Balancin O. Prediction of steel flow stresses under hot working conditions. Mater Res. 2005;8(3):309-15.

7. Jonas JJ, Quelennec X, Jiang L, Martin É. The Avrami kinetics of dynamic recrystallization. Acta Mater. 2009;57(9):274856.

8. Ivaniski TM, Epp J, Zoch H-W, Rocha AS. Austenitic grain size prediction in hot forging of a $20 \mathrm{MnCr} 5$ steel by numerical simulation using the JMAK model for industrial applications. Mater Res. 2019;22(5):e20190230.

9. Irani M, Joun M. Determination of JMAK dynamic recrystallization parameters through FEM optimization techniques. Comput Mater Sci. 2018;142:178-84.

10. Bylya O, Reshetov A, Stefani N, Rosochowska M, Blackwell P. Applicability of JMAK-type model for predicting microstructural evolution in nickel-based superalloys. Procedia Eng. 2017;207:1105-10.

11. Yang Z, Zhang F, Zheng C, Zhang M, Lv B, Qu L. Study on hot deformation behaviour and processing maps of low carbon bainitic steel. Mater Des. 2015;66:258-66.

12. Han Y, Sun Y, Zhang W, Chen H. Hot deformation and processing window optimization of a $70 \mathrm{MnSiCrMo}$ carbidefree bainitic steel. Materials (Basel). 2017;10(3):1-18.

13. Han Y, Yan S, Yin B, Li H, Ran X. Effects of temperature and strain rate on the dynamic recrystallization of a mediumhigh-carbon high-silicon bainitic steel during hot deformation. Vacuum. 2018;148:78-87.

14. Lemos Bevilaqua W, Epp J, Meyer H, Da Silva Rocha A, Roelofs H. In situ investigation of the bainitic transformation from deformed austenite during continuous cooling in a low carbon Mn-Si-Cr-Mo steel. Metall Mater Trans, A Phys Metall Mater Sci. 2020;51:3627-37.

15. Xiao YH, Guo C. Constitutive modelling for high temperature behavior of $1 \mathrm{Cr} 12 \mathrm{Ni} 3 \mathrm{Mo} 2 \mathrm{VNbN}$ martensitic steel. Mater Sci Eng A. 2011;528(15):5081-7.

16. Mirzadeh H, Najafizadeh A. Extrapolation of flow curves at hot working conditions. Mater Sci Eng A. 2010;527(78):1856-60.

17. Chen XM, Lin YC, Wen D-X, Zhang J-L, He M. Dynamic recrystallization behavior of a typical nickel-based superalloy during hot deformation. Mater Des. 2014;57:568-77.

18. Prasad YVRK, Rao KP, Sasidhara S. Hot working guide: a compendium of processing maps. Materials Park: ASM International; 2015.

19. Han Y, Qiao G, Sun JP, Zou D. A comparative study on constitutive relationship of as-cast $904 \mathrm{~L}$ austenitic stainless steel during hot deformation based on Arrhenius-type and artificial neural network models. Comput Mater Sci. 2013;67:93-103. 
20. Liu M, Ma Q, Luo J. Microstructure evolution and flow stress model of a $20 \mathrm{Mn} 5$ hollow steel ingot during hot compression. Materials (Basel). 2018;11(4):1-15.

21. Sellars CM, Whiteman JA. Recrystallization and grain growth in hot rolling. Met Sci. 1978;13(3-4):187-94.

22. Zou DN, Liu R, Han Y, Zhang W, Wu K, Liu XH. On dynamic recrystallisation under hot working of superaustenitic stainless steel. Mater Sci Technol. 2014;30(4):411-7.

23. Estrin Y, Mecking H. A unified phenomenological description of work hardening and creep based on one-parameter models. Acta Metall. 1984;32(1):57-70.
24. Silva ES, Sousa RC, Jorge AM Jr, Balancin O. Hot deformation behavior of an $\mathrm{Nb}$ - and N-bearing austenitic stainless steel biomaterial. Mater Sci Eng A. 2012;543:69-75.

25. Seki I, Nagata K. Lattice constant of iron and austenite including its supersaturation phase of carbon. ISIJ Int. 2005;45(12):178994. http://dx.doi.org/10.2355/isijinternational.45.1789.

26. Laasraoui A, Jonas JJ. Prediction of steel flow stresses at high temperatures and strain rates. Metall Mater Trans, A Phys Metall Mater Sci. 1991;22(7):1545-58. http://dx.doi. org/10.1007/BF02667368. 